\title{
Genotyping of Rotavirus in Neonatal Calves with Acute Gastroenteritis in Iraq
}

\author{
Atheer Abdulrazzaq Abdulazeez, Modher Nagem Abed \\ Department of Microbiology, College of Veterinary Medicine, University of Baghdad, Baghdad, Iraq \\ Email: aaldouri96@yahoo.com
}

How to cite this paper: Abdulazeez, A.A. and Abed, M.N. (2017) Genotyping of Rotavirus in Neonatal Calves with Acute Gastroenteritis in Iraq. Advances in Microbiology, 7, 863-870.

https://doi.org/10.4236/aim.2017.712066

Received: October 26, 2017

Accepted: December 23, 2017

Published: December 26, 2017

Copyright $\odot 2017$ by authors and Scientific Research Publishing Inc. This work is licensed under the Creative Commons Attribution International License (CC BY 4.0).

http://creativecommons.org/licenses/by/4.0/

(c) (i) Open Access

\begin{abstract}
Globally, Rotavirus is the common major etiologic agents of diarrhea in infant, young children and neonatal calves. It is very important to early diagnose the disease for effective treatment. The objective of this study was to determine the prevalence, molecular characteristics, and the effect of rotavirus strains for severe gastroenteritis in neonatal calves in five Iraqi governorates (Al-Qadissiya, Babel, Kerbala, Missan, Wassit). A total of 125-stool specimens were examined, it have been collected from calves form the period between November 2015 to March 2016. The ages were ranging from 6 to 60 weeks. The specimens were examined using Chromatographic Immunoassay, enzyme-linked immunosorbent assay (ELISA) and Polymerase-chain reaction (PCR). Our results gave us 67 (53.6\%) positive by chromatographic immunoassay, 45 (36\%) positive by ELISA and $32(25.6 \%)$ positive by PCR. Genotyping were analyzed by multiplex PCR. Genotype combination G1P[8] was (30\%) followed by G1P[4] (20\%), G3P[4] (20\%), G2P[4] (10\%), G2P[8] (10\%) and G9P[4] (10\%). Such information will not only aid in seeking advocacy for introducing rotavirus vaccine in national immunization program in Iraq, but will also help in the evaluation of the efficacy of these vaccines in relation to the rotavirus genotyping circulation.
\end{abstract}

\section{Keywords}

Rotavirus, Genotyping, Calve, Diagnosis, PCR

\section{Introduction}

The wheel-like (Latin rota $=$ wheel) particles of rotavirus were first determined as a human pathogen in 1973 by Bishop Ruth [1]. When characteristic particles were noticed in the cytoplasm of duodenal epithelial cells got from young children severing from acute diarrhea [2]. Rotavirus is a $65-70 \mathrm{~nm}$ RNA virus of the 
family Reoviridae, icosahedral, with segmented double-stranded, it is classified into seven serogroups A - G; Group A subtypes 1, 2, 3, 4 constitute the main human pathogens and Group B - E infects mainly animals and birds, the rotaviruses own 3 protein shells surrounding the genome, this triple layered structure have capsomeres look like the spokes of a wheel radiating from the inner to the outer capsid [3]. Viral pathogens account for approximately $70 \%$ of episodes of acute infectious diarrhea in children, and rotavirus is the most commonly implicated virus, Group A rotaviruses are responsible for 30\% - 60\% of all cases of severe watery diarrhea in young children and animals [2]. Diarrhea caused by rotavirus could not be recognized clinically because the clinical symptoms (diarrhea, vomiting, fever, and dehydration) are not entirely associated with rotavirus infection [4]. The most commonly used tests in diagnosing rotavirus infections are electron microscopy, latex agglutination test, and enzyme-linked immunosorbent assay (ELISA), polyacrylamide gel electrophoresis, and immune chromatographic and polymerase chain reaction (PCR) tests [5]. Since there are many combinations of $\mathrm{P}$ and $\mathrm{G}$ genotypes in bovine group A rotavirus (BRV), research into the genotyping of $\mathrm{BRV}$ is very important for preventive veterinary medicine and, more specifically, for the development of a vaccine. It is also important from the point of view of ecology and public health, because interspecies transmission from cattle to humans and from humans to cattle have been reported. Particularly rotavirus P[11], G10 strains, which are commonly found in cattle had frequently been associated with asymptomatic neonatal infections in Tamil Nadu, India [6].

The aim of the present study was to identify the genotype distribution of bovine rotavirus in five governorates in Iraq and to know the vaccine isolates depending to the genotyping of rotavirus.

\section{Materials and Methods}

A total of 125 stool samples obtained From November 2015 to March 2016, from neonatal calves with acute gastroenteritis were randomly collected at 5 Iraqi governorates, for each governorates 25 samples have been taken (Babel, Kerbala, Missan, Qadissiya, and Wassit). $10 \mathrm{gm}$ of yellow to white liquid with fatty droplet feces were examined under microscope and collected directly into sterile disposable plastic containers by rectal stimulation then stored in a cool box and transported to the laboratory, where each sample was added to specimen collection tube with extraction buffer that used in chromatographic immunoassay. The feces samples were centrifuged for 5 minute to remove particulates at 3000 $\mathrm{rpm}$. Thereafter, the supernatants were stored at $-20^{\circ} \mathrm{C}$ until the assay day.

The chromatographic immunoassay performed to the first method that we used to detect the rotavirus in stool samples (ABON Biopharm Co., Ltd., Hangzhou, China). The qualitative Rotavirus assay ELISA was performed to the second method, which detect the rotavirus (RV) antigen (Ag), the ELISA was carried out using Cusabio kit (Cusabio Biotech Co., Ltd, China). Chromatographic immunoassay and ELISA were performed according to the manufacturers' 
instructions. While the PCR and Genotyping were evaluated by using (AccuPower PCR Premix of Bioneer Corporation) from Republic of Korea. The primers as it shown in (Table 1 and Table 2) and thermo-cycler conditions were performed according to the manufacturers' instructions that we used in RT-PCR and Genotyping for both $\mathrm{G}$ and $\mathrm{P}$ were performed according to World Health Organization manual [7].

\section{Results}

The present study showed the relationship among three diagnosis tests for detecting rotavirus serotype in Iraq. Chromatographic immunoassay revealed 55 (44\%) The highest positive results were in Missan 60\% (15 of 25 samples); however the lowest incidence was in AlQadissiya 28\% (7 of 25 samples) by using chromatographic immunoassay.

Table 1. The primers and their sequences that are specific for human rotavirus genotyping. P-type-specific oligonucleotide Primers. World Health Organization [7].

\begin{tabular}{ccccc}
\hline No. & Primer Name & Type & Primer sequences (5'-3') & Size Product \\
\hline & & \multicolumn{2}{c}{ First amplification consensus } \\
1 & CON3 F & VP4 Forward & TGGCTTCGCTCATTTATAGACA & 276 bp \\
2 & CON 2 R & VP4 Reverse & ATTTCGGACCATTTATAACC & \\
& & Second amplification genotyping primers & $483 \mathrm{bp}$ \\
1 & $2 \mathrm{~T}-1$ & $\mathrm{P}[4]$ & CTATTGTTAGAGGTTAGAGTC & $267 \mathrm{bp}$ \\
2 & $3 \mathrm{~T}-1$ & $\mathrm{P}[6]$ & TGTTGATTAGTTGGATAA & $345 \mathrm{bp}$ \\
3 & $1 \mathrm{~T}-1$ & $\mathrm{P}[8]$ & TCTACTTGGATAACGTGC & $391 \mathrm{bp}$ \\
\hline
\end{tabular}

Table 2. The primers and their sequences that are specific for human rotavirus genotyping.G-type-specific oligonucleotide Primers.

\begin{tabular}{ccccc}
\hline No. & Primer Name & Type & Primer sequences (5'-3') & Size Product \\
\hline & & \multicolumn{2}{c}{ First amplification consensus } \\
1 & 9CON 1F & VP7 Forward & TAGCTCCTTTTAATGTATGG & 897 bp \\
2 & VP7 R & VP7 Reverse & AACTTGCCACCATTTTTTCC & \\
& & Second amplification genotyping primers & \\
1 & aBT1 & G1 & CAAGTACTCAAATCAATGATGG & $158 \mathrm{bp}$ \\
2 & Act2 & G2 & CAATGATATTAAACATTTTCTGTG & $244 \mathrm{bp}$ \\
3 & G3-AUST & G3 & ACGAACTCAACACGAGARG & $464 \mathrm{bp}$ \\
4 & aDT4 & G4 & CGTTTCTGGTGAGGAGTTG & $403 \mathrm{bp}$ \\
5 & aAT8 & G8 & GTCACACCATTTGTAAATTCG & $651 \mathrm{bp}$ \\
6 & G9 or Mg9 & G9 & GTTGATGTGACTAYAAATAC & $110 \mathrm{bp}$ \\
\hline
\end{tabular}


Nevertheless, ELISA test revealed 53 (42\%) positive samples. The highest positive result was recorded in Missan 60\% (15 of 25 samples), and the lowest in AlQadissiya 20\% (5 of 25 samples). In this study, PCR technique was used for detection the two outer layer protein's VP7 and VP4. All animals samples, which had been tested using Chromatographic and ELISA, were tested by using PCR 47 (38\%) were positive. The higher percent was in Missan 48\% (12 of 25 samples) and the lowest was in AlQadissiya 28\% (7 of 25 samples) as it shown in Table 3.

The multiplex polymerase chain reaction technique was used for genotyping of both VP7 (a glycoprotein), VP4 (a protease-sensitive protein) were revealed G1P[8] was commonly detected (30\%) in animal samples followed by G1P[4] (20\%), G3P[4] (20\%), G2P[4] (10\%), G2P[8] (10\%) and G9P[4] (10\%) (Figure 1).

Table 3. Comparison of the results that have been obtained from three testing method for rotavirus in 125 bovine fecal samples.

\begin{tabular}{|c|c|c|c|}
\hline SITE & Chromatographic Immunoassay (\%) & ELISA (\%) & PCR (\%) \\
\hline \multicolumn{4}{|l|}{ AlQadissiya } \\
\hline Positive & $7(28 \%)$ & $5(20 \%)$ & $7(28 \%)$ \\
\hline Negative & $18(72 \%)$ & $20(80 \%)$ & $18(72 \%)$ \\
\hline Total & $25(100 \%)$ & $25(100 \%)$ & $25(100 \%)$ \\
\hline \multicolumn{4}{|l|}{ Babel } \\
\hline Positive & $11(44 \%)$ & $11(44 \%)$ & $9(36 \%)$ \\
\hline Negative & $14(56 \%)$ & $14(56 \%)$ & $16(64 \%)$ \\
\hline Total & $25(100 \%)$ & $25(100 \%)$ & $25(100 \%)$ \\
\hline \multicolumn{4}{|l|}{ Kerbala } \\
\hline Positive & $9(36 \%)$ & $9(36 \%)$ & $8(32 \%)$ \\
\hline Negative & $16(64 \%)$ & $16(64 \%)$ & $17(68 \%)$ \\
\hline Total & $25(100 \%)$ & $25(100 \%)$ & $25(100 \%)$ \\
\hline \multicolumn{4}{|l|}{ Missan } \\
\hline Positive & $15(60 \%)$ & $15(60 \%)$ & $12(48 \%)$ \\
\hline Negative & $10(40 \%)$ & $10(40 \%)$ & $13(52 \%)$ \\
\hline Total & $25(100 \%)$ & $25(100 \%)$ & $25(100 \%)$ \\
\hline \multicolumn{4}{|l|}{ Wasit } \\
\hline Positive & $13(52 \%)$ & $13(52 \%)$ & $11(44 \%)$ \\
\hline Negative & $12(48 \%)$ & $12(48 \%)$ & $14(56 \%)$ \\
\hline Total & $25(100 \%)$ & $25(100 \%)$ & $5(100 \%)$ \\
\hline$\Sigma$ Positive & $55(44 \%)$ & $53(42 \%)$ & $47(38 \%)$ \\
\hline$\Sigma$ Negative & 70 (56\%) & $72(58 \%)$ & $78(62 \%)$ \\
\hline
\end{tabular}



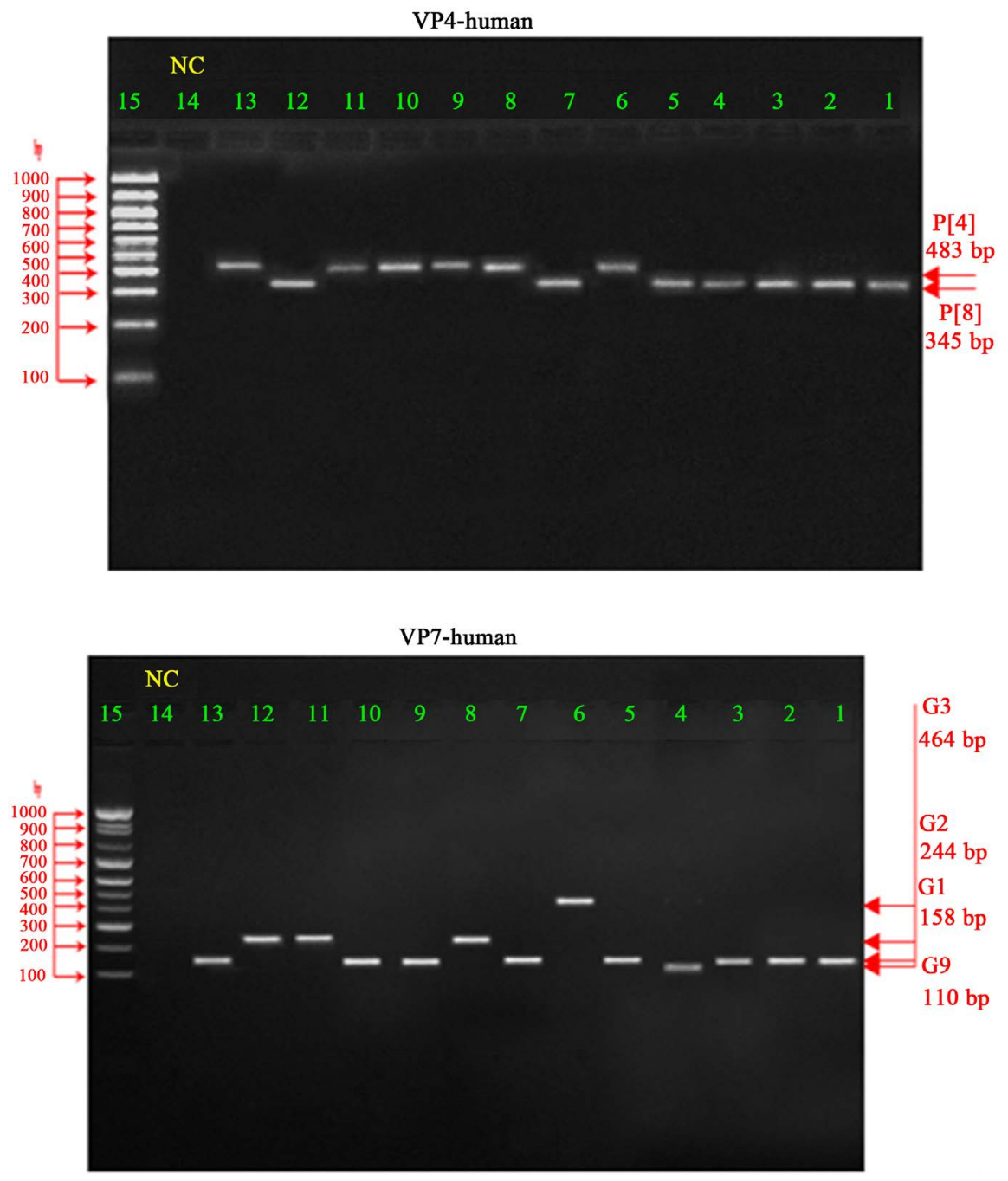

Figure 1. The presence of $\mathrm{G}$ and $\mathrm{P}$ of animal samples in the five governorates.

\section{Discussion}

Chromatographic Immunoassay and ELISA are the straightforward and effortless standard methods for detection of rotavirus. These methods, however, require low cost equipment and simple experience, which is available in many laboratories. Some researchers for detecting rotavirus infection have used ELISA and PCR [8]. Our study suggested that chromatographic immunoassay is a possible method for examining stool samples that have been collected from animal with suspected diarrhea that be infected by rotavirus.

This study suggested that chromatographic immunoassay was screening test which can be performed without need of trained personnel or expensive equipment also it can read with naked eye, making it easy to perform in every laboratory. The positive results that have been obtained by ELISA method were approximately similar to the results by using chromatographic method, which is probably responsible to the reported superior accuracy of the method. By chromatographic immunoassay 55 (44\%) were positive samples, and by ELISA revealed 53 
(42\%) positives. This study agrees with a study that conducted in American United States examined 63 feces samples, which were collected from infant that infected with diarrhea, by chromatographic immunoassay and Rotazyme ELISA, the obtained results were 37 positive samples and 26 negative and it were 36 positive and 27 negative by ELISA [9]. Moreover, it agrees with a study conducted in Iran, which detected Rotavirus by chromatographic immunoassay and ELISA, which were $(34.8 \%)$, (28.3\%) positive samples respectively. The sensitivity, specificity of ELISA were $94.6 \%, 94.4 \%$ and to Chromatographic immunoassay were $82.6 \%, 81.6 \%$ respectively [10]. In addition, another research in Babylon, which obtained the rotavirus in 108 out of 236 samples (45.76\%) by ELISA and 112 out of 236 samples (47.45\%) by Chromatographic immunoassay. Results of rotavirus detection by Chromatographic immunoassay for the sensitivity and specificity were $(97.2 \%)$, (94.5\%) respectively, whereas by ELISA the sensitivity and specificity were $97.2 \%, 97.1 \%$, respectively $[11]$.

The sensitivity and specificity of the chromatographic immunoassay are $99.9 \%$ and $97.8 \%$ respectively. The test for ELISA is very high (sensitivity at least 98\%) and (excellent specificity 98\%). The kappa between PCR and Chromatographic 0.42 while the kappa between PCR and ELISA is 0.45 the kappa percent refer to a good agreement between these three tests.

In the present study, consensus primers were used to amplify the partial-length copies of the rotavirus VP4 gene which yielded the expected amplicon size of 876 bp and full length copies of VP7 gene, which yielded 897 bp product in all the nine field samples, which in turn was used as a template in multiplex PCR to identify all the possible $\mathrm{G}$ and $\mathrm{P}$ genotype present in bovine rotavirus strains as reported by [12].

The result of present study in genotyping G1P[8], G1P[4] was found to be the most frequently infected in animal samples, whereas the G2P[4], G2P [8] were the lowest strain. Our results were identify $G$ and $P$ genotypes were similar to the results presented [13], they showed that G1P[8] and G1P[4] were most frequent in Iran followed by P[8] (66.4\%) then P[4] (9.2\%) and G1 (76.3\%). In another study conducted in Saudi Arabia [14], the higher rate of identified genotype were G1P[8] (44\%) followed by G2P[4] (20\%).

The G10P[11] genotype strain was an important genotype of group A BRV because of its zoonotic transmission from humans to cattle and also from cattle to humans, as reported by [6]. In this study, we describe the detection of bovine P[11], G10 genotype strains in Tamil Nadu which may be recognized as an important contributor to the diversity of rotaviruses found in human infections. The close interaction of the majority of the Indian population, particularly that of the Tamil Nadu population with cattle, makes possible the transmission of rotavirus from cattle to children. In conclusion multiplex PCR, which was the confirmatory serotyping for identification and typing of rotavirus genotypes, had facilitated the studies on the occurrence and distribution of individual $\mathrm{P}$ and $\mathrm{G}$ genotypes of the bovine population in 5 governorate of Iraq, in which, G1 
[P8], a zoonotic important bovine genotype, was found to be present. P and G genotype associations most commonly identified in cattle were P[5], G6, P[11], G10 and P[1], G6, as reported by [15]. Hence, in this study, we attempted to discover the associations of P[5], G6 and P[11], G10 which were very common genotypes observed in bovine rotavirus, as reported by [16]. Relying on current study's results, PCR presented the greatest sensitivity and specificity while ELISA and chromatographic immunoassay kits were not as sensitive and specific as PCR test, that were the highest specific [17].

\section{Acknowledgements}

We are grateful to the many friends and colleagues who generously contributed their time and effort to help us make this paper as accurate and useful as possible. The support of our other colleagues at the ministry of health (CPHL) Dr. Faisal Al hamadani and Dr. Iman. M. Aufi who help us to use the lap for our research.

\section{References}

[1] Bishop, R.F., Barnes, G.L., Cipriani, E. and Jennifer, S. (1983) Clinical Immunity after Neonatal Rotavirus Infection-A Prospective Longitudinal Study in Young Children. The New England Journal of Medicine, 309, 72-76. https://doi.org/10.1056/NEJM198307143090203

[2] Abu EL-Amreen, F.H. (2006) Application of Polymerase Chain Reaction (PCR), Bacteriological Culture, Immunoassay, and Microscopy for Detection and Identification of Gastrointestinal Pathogens in Children. M.Sc. Thesis, Collage of Sci. Med. Gaz. Univ.

[3] Clark, B. and McKendrick, M. (2004) A Review of Viral Gastroenteritis. Current Opinion in Infectious Diseases, 17, 461-469.

[4] Nguyen, T.V., Le Van, P., Le Huy, C. and Weintraub, A. (2004) Diarrhea Caused by Rotavirus in Children Less than 5 Years of Age in Hanoi. Journal of Clinical Microbiology, 42, 5745-5750. https://doi.org/10.1128/JCM.42.12.5745-5750.2004

[5] Altindis, M., Yavru, S., Simsek, A., Ozkul, A., Ceri, A. and Koc, H. (2004) Rotavirus Infection in Children with Acute Diarrhea as Detected by Latex Agglutination, ELISA and Polyacrylamide Gel Electrophoresis. Indian Pediatrics, 41, 590-594.

[6] Iturriza-Gomara, I., King, G., Mammen, A., Jana, A.K., Abraham, M., Desselberger, U., Brown, D. and Gray, J. (2004) Characterization of G10P[11] Rotaviruses Causing Acute Gastroentritis in Neonates and Infants in Vellore, India. Journal of Clinical Microbiology, 41, 2541-2547.

https://doi.org/10.1128/JCM.42.6.2541-2547.2004

[7] World Health Organization (WHO) (2009) Manual of Rotavirus Detection and Characterization Method.

[8] Guandalini, S. and Vaziri, H. (2011) Diarrhea: Diagnostic and Therapeutic Advances. Humana Press, Springer Science Business Media. 233 Spring Street. New York. USA. Infect Dis., 17, 461-469. https://doi.org/10.1007/978-1-60761-183-7

[9] Al-Yousif, Y., Anderson, J., Chard-Bergstrom, C., Bustamante, A., Muenzenberger, M., Austin, K. and Kapil, S. (2001) Evaluation of a Latex Agglutination Kit (Virogen Rotatest) for Detection of Bovine Rotavirus in Fecal Samples. Clinical and Diagnostic Laboratory Immunology, 8, 496-498. 
[10] Pereira, L.A., Raboni, S.M., Meri, B.N., Vidal, L.R., de Almeida, S.M., Debur, M.C. and Cruz, C. (2011) Rotavirus Infection in a Tertiary Hospital: Laboratory Diagnosis and Impact of Immunization on Pediatric Hospitalization. The Brazilian Journal of Infectious Diseases, 15, 215-219. https://doi.org/10.1016/S1413-8670(11)70178-7

[11] AL-Khafaji, Y.A. and AL-Jiboury, H.J. (2013) Detection of Rotavirus in Diarrhea Stool Samples of Children with Acute Gastroenteritis in Babylon Governorate, Iraq. Department of Microbiology, College of Dentistry, University of Babylon. International Research Journal of Microbiology (IRJM), 4, 84-88.

[12] Alfieri, A.F., Alfieri, A.A., Barreiors, M.A., Letil, J.P.G. and Richtzenhain, L.J. (2004) G and P Genotypes of Group A Rotavirus Strains Circulating in Calves in Brazil, 1996-1999. Veterinary Microbiology, 99, 167-173.

https://doi.org/10.1016/j.vetmic.2003.10.029

[13] Khoshdel, A., Parvin, N., Doosti, A. and Eshraghi, A. (2014) Prevalence and Molecular Characterization of Rotaviruses as Causes of Nosocomial Diarrhea in Children. The Turkish Journal of Pediatrics, 56, 469-474.

[14] Kheyami, A.M., Toyoko, N., Osamu, N., Winifred, D., Hart, C.A. and Nigel, A.C. (2008) Molecular Epidemiology of Rotavirus Diarrhea among Children in Saudi Arabia: First Detection of G9 and G12 Strains. Journal of Clinical Microbiology, 46, 1185-1191. https://doi.org/10.1128/JCM.02244-07

[15] Snodgrass, D.R., Fitzgeraid, T.A., Campbell, I., Scott, F., Browning, G.F., Miller, D.L., Herring, A.J. and Greenberg, H.B. (1990) Rotavirus Serotypes 6 and 10 Predominate in Cattle. Journal of Clinical Microbiology, 8, 504-507.

[16] Ishizaki, H., Sakai, T., Shirahata, T., Taniguchi, K., Urasawa, T., Urasawa, S. and Goto, H. (1996) The Distribution of G and P Genotypes within Solates of Bovine Rotavirus in Japan. Veterinary Microbiology, 48, 367-372. https://doi.org/10.1016/0378-1135(95)00168-9

[17] Saravanan, M., Parthiban, M. and Ramadass, P. (2006) Genotyping of Rotavirus of Neonatal Calves by Nested-Multiplex PCR in India. Veterinarski arhiv, 76, 497-505. 